\title{
"Chimera" fully covered self-expandable metal stent for refractory esophageal anastomotic leak
}

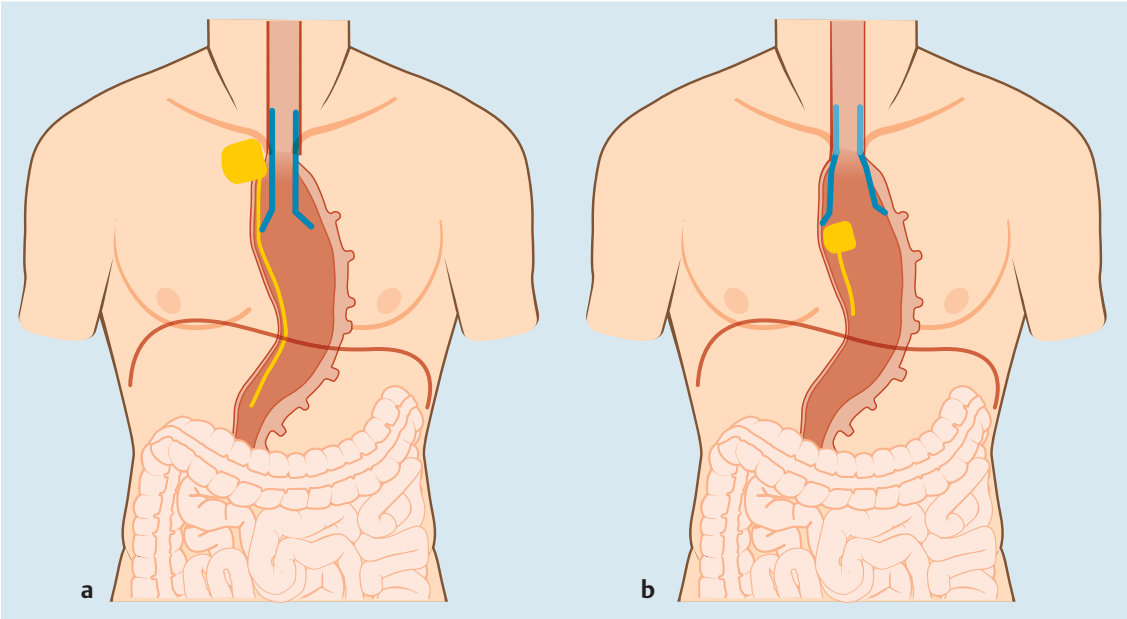

Fig. 1 a In a 62-year-old man who previously underwent distal esophagectomy with gastroesophageal intrathoracic anastomosis for esophageal tumor (Ivor-Lewis intervention), the standard stent allows gastric reflux into a paraesophageal collection resulting from partial dehiscence of the anastomosis. b The "chimera" stent blocks gastric reflux into the collection.

Self-expandable stents are used to treat postoperative leaks and fistulas in the upper gastrointestinal tract [1 - 3]. However, a discrepancy between stent size and lumen size may lead to insufficient sealing of a leak, requiring further surgical intervention $[4,5]$. The main reason why this problem occurs is the relatively small diameter of commonly used commercial stents [5].

A 62-year-old man underwent distal esophagectomy with gastroesophageal intrathoracic anastomosis for esophageal tumor (Ivor-Lewis intervention) at another hospital. During his postoperative course, a partial dehiscence of the anastomosis developed, with the formation of a paraesophageal collection. The fluid collection was drained endoscopically with a 7-Fr nasobiliary drain inserted through the dehiscence.

Because this procedure was ineffective, the patient was admitted to our hospital for the insertion of a fully covered esophageal stent. Before placement of the stent, percutaneous transthoracic drainage of the paraesophageal collection was performed. Then, a fully covered, self-expandable esophageal metal stent (Euromedical, Italy), $10 \mathrm{~cm}$ long and $18 \mathrm{~mm}$ in diameter, was placed to cover the internal orifice of the fistula. However, the stent diameter was not large enough for the stent to adhere to the tubularized gastric wall, so that upstream gastric reflux into the mediastinal collection prevented complete healing of the fistula ( $\bullet$ Fig. 1 a).

To increase the diameter of the distal end of the stent, we decided to replace the original stent with a "chimera" stent, created by suturing together an 18-mm-diameter fully covered self-expandable metal stent (Euromedical) and a 28- to 34-mm-diameter fully covered self-expandable colonic metal stent (Euromedical), which was added distally to allow complete adherence to the gastric wall ( $\bullet$ Fig. 2 and $\odot$ Fig.3). The fistula outflow stopped immediately ( $\bullet$ Fig. 1 b), and the stent was removed 3 weeks later ( $\bullet$ Fig. 4).

This case underscores the importance of choosing a stent of the correct size, depending on the site of placement. In this situation, a perfect fit within the tubularized gastric wall was mandatory and could not be not achieved with a standard commercial stent. We suggest that this technical "trick" could be considered in selected patients and expert hands so that a stent of the best size relative to the lumen size can be obtained.

\section{Endoscopy_UCTN_Code_TTT_1AO_2AI}

\section{Competing interests: None}

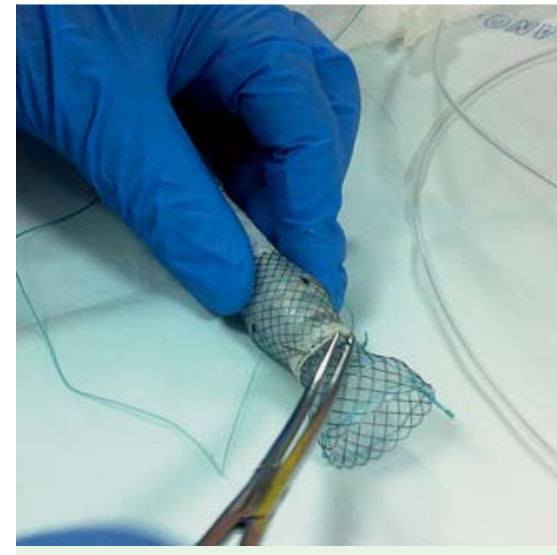

Fig. 2 The two parts, from different stents, are sutured together.

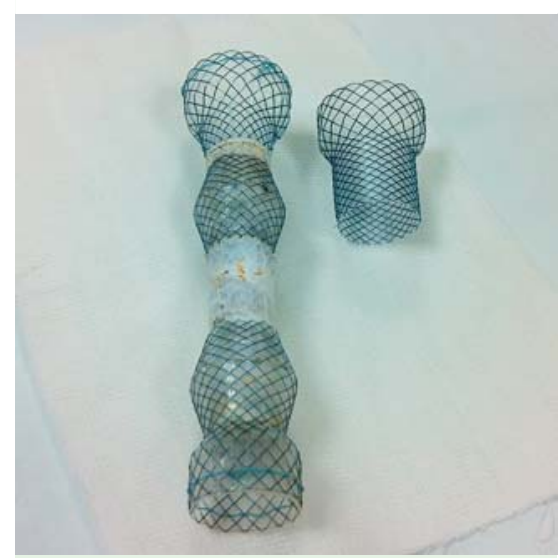

Fig. 3 The "chimera" stent is ready to be introduced (the upper part for the esophagus and the lower part for the tubularized stomach).

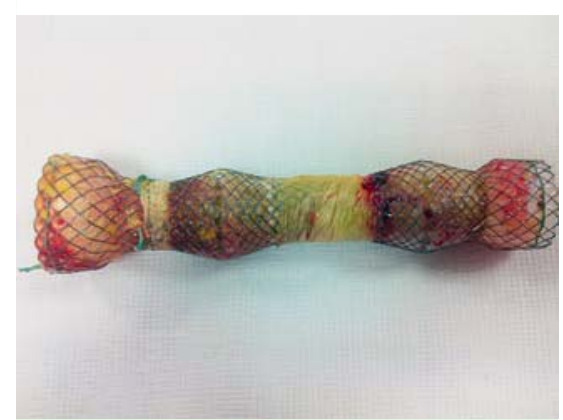

Fig. 4 The stent has been removed after complete fistula healing (right part was placed in the esophageal site, and left part in the gastric site). 


\section{Massimiliano Mutignani ${ }^{1}$,} Lorenzo Dioscoridi ${ }^{1}$, Raffaele Manta', Edoardo Forti ${ }^{1}$, Francesco Pugliese ${ }^{1}$, Domenico D'Ugo², Roberto Persiani²

${ }^{1}$ Digestive Endoscopy Unit, Niguarda Ca' Granda Hospital, Milan, Italy

2 UOC General Surgery, Università Cattolica del Sacro Cuore, Rome, Italy

\section{References}

1 Raimondo D, Sinagra E, Facella $T$ et al. Selfexpandable metal stent placement for closure of a leak after total gastrectomy for gastric cancer: report on three cases and review of the literature. Case Rep Gastrointest Med 2014; 2014: 409283

2 Fischer A, Bausch D, Richter-Schrag HJ. Use of a specially designed partially covered self-expandable metal stent (PSEMS) with a $40-\mathrm{mm}$ diameter for the treatment of upper gastrointestinal suture or staple line leaks in 11 cases. Surg Endosc 2013; 27: 642-647

3 van Boeckel PG, Dua KS, Wuesten BL et al. Fully covered self-expandable metal stents (SEMS), partially covered SEMS and selfexpandable plastic stents for the treatment of benign esophageal ruptures and anastomotic leaks. BMC Gastroenterol 2012; 12: 19

4 Dasari BV, Neely D, Kennedy A et al. The role of esophageal stents in the management of esophageal anastomotic leaks and benign esophageal perforations. Ann Surg 2014; 259: $852-860$

5 von Boeckel PG, Sijbring A, Vleggaar FP et al. Systematic review: temporary stent placement for benign rupture or anastomotic leak of the oesophagus. Aliment Pharmacol Ther 2011; 33: $1292-1301$

\section{Bibliography}

Dol http://dx.doi.org/

10.1055/s-0034-1392238

Endoscopy 2015; 47: E376-E377

(c) Georg Thieme Verlag KG

Stuttgart · New York

ISSN 0013-726X

\section{Corresponding author}

Raffaele Manta, MD

Endoscopy Unit

Niguarda Ca' Granda Hospital

Piazza dell'Ospedale Maggiore, 3

20162 Milano

Italy

Fax: +39-02-64442911

r.manta@libero.it 